\title{
Tissue Factor Expression in Human Arterial Smooth Muscle Cells TF is Present in Three Cellular Pools after Growth Factor Stimulation
}

\author{
Alison D. Schecter, ${ }^{\S}$ Peter L.A. Giesen, ${ }^{\ddagger}$ O. Taby, ${ }^{\S \ddagger}$ Claire-Lise Rosenfield, ${ }^{\star}$ Maria Rossikhina, ${ }^{\star \S}$ Billie S. Fyfe,, \\ D. Stave Kohtz, J John T. Fallon, ${ }^{\star \S \|}$ Yale Nemerson, ${ }^{\S \ddagger}$ and Mark B. Taubman ${ }^{\star \S}$

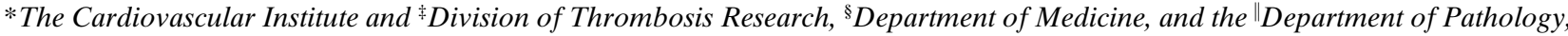 \\ The Mount Sinai School of Medicine, New York 10029
}

\section{Abstract}

Tissue factor (TF) is a transmembrane glycoprotein that initiates the coagulation cascade. Because of the potential role of TF in mediating arterial thrombosis, we have examined its expression in human aortic and coronary artery smooth muscle cells (SMC). TF mRNA and protein were induced in SMC by a variety of growth agonists. Exposure to PDGF AA or BB for 30 min provided all of the necessary signals for induction of TF mRNA and protein. This result was consistent with nuclear runoff analyses, demonstrating that PDGF-induced TF transcription occurred within $30 \mathrm{~min}$. A newly developed assay involving binding of digoxigeninlabeled FVIIa (DigVIIa) and digoxigenin-labeled Factor X (DigX) was used to localize cellular TF. By light and confocal microscopy, prominent TF staining was seen in the perinuclear cytoplasm beginning $2 \mathrm{~h}$ after agonist treatment and persisting for 10-12 h. Surface TF activity, measured on SMC monolayers under flow conditions, increased transiently, peaking 4-6 $\mathrm{h}$ after agonist stimulation and returning to baseline within $16 \mathrm{~h}$. Peak surface TF activity was only $\sim 20 \%$ of total TF activity measured in cell lysates. Surface TF-blocking experiments demonstrated that the remaining TF was found as encrypted surface TF, and also in an intracellular pool. The relatively short-lived surface expression of TF may be critical for limiting the thrombotic potential of intact SMC exposed to growth factor stimulation. In contrast, the encrypted surface and intracellular pools may provide a rich source of TF under conditions associated with SMC damage, such as during atherosclerotic plaque rupture or balloon arterial injury. (J. Clin. Invest. 1997. 100:2276-2285.) Key words: thrombosis - growth factors $\bullet$ flow chamber $\bullet$ human arterial smooth muscle $\bullet$ Factor VII

\section{Introduction}

Tissue factor (TF) ${ }^{1}$ initiates the coagulation cascade by complexing with Factor VIIa (FVIIa) to form an enzymatic complex cleaving Factors X (FX) and IX to Xa and IXa, respec-

Address correspondence to Mark B. Taubman, M.D., Box 1269, Mount Sinai School of Medicine, One Gustave L. Levy Place, New York, NY 10029. Phone: 212-241-0047; FAX: 212-860-7032.

Received for publication 4 February 1997 and accepted in revised form 15 September 1997.

J. Clin. Invest.

(C) The American Society for Clinical Investigation, Inc. 0021-9738/97/11/2276/10 \$2.00

Volume 100, Number 9, November 1997, 2276-2285

http://www.jci.org tively (1-3). In normal arteries, little or no TF is found in the intima or media, whereas TF is abundant in the adventitia. In animal models of balloon arterial injury, TF is rapidly induced in the smooth muscle cells (SMC) of the media $(4,5)$, and accumulates in the SMC of the developing neointima (6). Induction of TF in SMC appears to be primarily responsible for the prolonged procoagulant activity in rabbit balloon-injured aortas (7). TF antigen is present in human atherosclerotic plaques $(6,8-11)$. In the plaque, TF antigen is found within macrophages, SMC, endothelial cells, extracellular matrix, and most abundantly in the acellular lipid-rich core (6). Studies using human coronary atherectomy specimens have demonstrated that at least some of the TF present in the plaque is active (9). $\mathrm{TF}$ antibody staining of atherectomy specimens from patients with stable and unstable angina identified SMC in the plaque as an independent predictor of TF content in patients with unstable angina (10). Ex vivo perfusion studies have also suggested the presence of TF activity in isolated plaque components, particularly in the lipid-rich core (12). The relative contribution of SMC and macrophages to active TF in the plaque, particularly in the predominantly acellular lipid-rich core, remains to be determined. These studies have implicated $\mathrm{TF}$ as the key mediator of thrombosis associated with both plaque rupture, as seen in acute myocardial infarction and unstable angina $(9,10,12)$, and acute arterial injury, such as that produced by balloon angioplasty or coronary atherectomy ( 9 , 11, 12).

Induction of TF in human endothelial cells and monocyte/ macrophages has been extensively studied $(13,14)$. In contrast, little is known about regulation of TF in human arterial SMC. Given the potential importance of arterial SMC as a source of TF in injured vessels and atherosclerotic plaques, we have examined TF expression in human aortic and coronary arterial SMC. We now report that TF is rapidly induced in cultured human arterial SMC by PDGF and thrombin. This induction is due primarily to an increase in TF transcription. Surface TF activity, measured on SMC monolayers under flow conditions, increases transiently, peaking 4-6 h after agonist stimulation and returning to baseline within $16 \mathrm{~h}$. Even at $4 \mathrm{~h}$, surface TF activity is only $\sim 20 \%$ of total TF activity measured in cell lysates. The remainder is contained intracellularly $(\sim 30 \%)$ and as latent surface TF $(\sim 50 \%)$. The relatively short-lived surface expression of TF may be critical to limiting the thrombotic potential of SMC after agonist stimulation. In addition, there is a substantial pool of potentially active TF that may be exposed

1. Abbreviations used in this paper: DigVIIa, digoxigenin-labeled FVIIa; DigX, digoxigenin-labeled FX; FVIIa, Factor VIIa; FX, Factor X; GAPDH, glyceraldehyde-3-phosphate-dehydrogenase; PC, phosphatidylcholine; PS, phosphatidylserine; S-NHS-A, sulfosuccinimidyl-acetate; SMC, smooth muscle cells; TBS, Tris buffered saline; $\mathrm{TF}$, tissue factor. 
by cellular injury, and which may contribute to the thrombogenicity of the injured vessel wall and the atherosclerotic plaque.

\section{Methods}

Growth factors and other reagents. Recombinant human PDGF AA and BB were purchased from Intergen Co. (Purchase, NY). A thrombin receptor peptide (racemic Ser-[p-fluoro]Phe-Arg-[cyclohexyl] AlaArg-Tyr-amide) was a generous gift from Dr. Barry S. Coller (Mount Sinai School of Medicine, New York). Angiotensin II, actinomycin D, and FCS were obtained from Sigma Chemical Co. (St. Louis, MO.). Human $\alpha$-thrombin was a generous gift from Dr. John W. Fenton II (Wadsworth Center for laboratories and research, New York State Department of Health, Albany, NY). Human recombinant FVIIa was a gift from Novo Nordisk A/S (Gentoffe, Denmark). Factor X was purified from human plasma (15). Digoxigenin-3-O-methylcarbonyl$\epsilon$-aminocaproic acid- $N$-hydroxy-succinimide ester (Dig-ester), sheep antidigoxigenin Fab antibody fragments conjugated to alkaline phosphatase (AP), peroxidase, or fluorescein, and AP detection kits were purchased from Boehringer Mannheim (Indianapolis, IN). Immunohistochemical grade 3,3'-diaminobenzidine (DAB) was purchased from BioGenex Labs (San Ramon, CA). Digoxigenin-labeled FVIIa (DigVIIa) and FX (DigX) were prepared from Dig-ester and recombinant FVIIa or FX, respectively, as previously described (6). Chromogenic substrate for activated FX, Ile-Pro-Arg- $p$-nitroaniline (IPRpNA) was synthesized in our laboratory. Sulfosuccinimidyl-acetate (S-NHS-A) was purchased from Pierce (Rockford, IL).

Cell culture. SMC were isolated from human thoracic aortas and coronary arteries harvested from explanted hearts at the time of cardiac transplantation. Primary coronary artery SMC were prepared as previously described for rat aortic SMC (16). For aortic SMC, the adventitia was removed, and the remaining arterial intima and media were cut into $1-\mathrm{cm}^{2}$ segments and placed in culture dishes with collagenase and $15 \%$ FCS. Cells were grown in DME medium supplemented with $10 \%$ FCS, $100 \mathrm{U} / \mathrm{ml}$ penicillin, and $100 \mu \mathrm{g} / \mathrm{ml}$ streptomycin. Aortic SMC were serially passaged before reaching confluence. Cells were identified as smooth muscle by their typical appearance on light microscopy and by immunostaining with anti-smooth muscle $\alpha$-actin. To produce quiescence, cells were incubated in a defined medium consisting of DME with BSA $(25 \mu \mathrm{g} / \mathrm{ml})$, ascorbate $(0.2 \mathrm{mM})$, insulin $(1 \mu \mathrm{M})$, and transferrin $(5 \mu \mathrm{g} / \mathrm{ml})$ (16). Measurements of $24-\mathrm{h}$ $\left[{ }^{3} \mathrm{H}\right]$ thymidine and $\left[{ }^{3} \mathrm{H}\right]$ leucine incorporation were as previously described (17). Experiments involving aortas were derived from passages 3-10, whereas those involving coronary arteries were performed on primary cultures.

RNA preparation and blot hybridization. Extraction of total RNA, agarose gel electrophoresis, and transfer to nitrocellulose and hybridization to $\left[{ }^{32} \mathrm{P}\right]$-labeled DNA were as previously described (16). Prehybridization and hybridization were performed at $42^{\circ} \mathrm{C}$. Final washes for all blots were in $0.1 \times \operatorname{SSC}(1 \times=0.15 \mathrm{M} \mathrm{NaCl} / 0.015 \mathrm{M}$ sodium citrate, $\mathrm{pH} 7.0$ ) and $0.1 \% \mathrm{SDS}$ at $65^{\circ} \mathrm{C}$ for $1 \mathrm{~h}$. A 1,200-bp insert from human TF (18) was labeled by random oligomer priming to a specific activity of $>10^{8} \mathrm{cpm} / \mathrm{mg}$, and was used at $2 \times 10^{6} \mathrm{cpm} / \mathrm{ml}$. Experiments shown in the figures represent blots in which all lanes had equal loading as confirmed by staining of $18 \mathrm{~s}$ and $28 \mathrm{~s}$ ribosomal RNA with ethidium bromide and by hybridization with fibronectin cDNA (17).

Nuclear runoff analysis. Transcription analyses were performed in triplicate as previously described (19). $48 \mathrm{~h}$ after receiving fresh medium, human aortic SMC $\left(2 \times 10^{7}\right.$ per sample $)$ were exposed to DME + BSA $(25 \mu \mathrm{g} / \mathrm{ml})$ alone or in the presence of PDGF BB $(10 \mathrm{ng} / \mathrm{ml})$. At 0,30 , and $120 \mathrm{~min}$, nuclei were harvested and frozen at $-80^{\circ} \mathrm{C}$. Nuclear runoff reactions were subsequently performed at room temperature for $30 \mathrm{~min}$ with $\left[{ }^{32} \mathrm{P}\right] \mathrm{UTP}$. The nuclei were treated with DNase I, added to a solution of guanidinium isothiocyanate, layered on a $5.7 \mathrm{M} \mathrm{CsCl}$ cushion, and centrifuged at 40,000 rpm for $18 \mathrm{~h}$. The labeled RNA was hybridized at $65^{\circ} \mathrm{C}$ to nitrocellulose filters containing $2 \mu \mathrm{g}$ of the full-length human tissue factor cDNA. Blots were washed at $68^{\circ} \mathrm{C}$ in $0.1 \times$ SSC. The same number of counts were hybridized to each filter. The pBluescript vector and the human glyceraldehyde-3-phosphate-dehydrogenase (GAPDH) cDNA were used as negative and positive controls, respectively. Normalized density was determined from triplicate experiments, and represents the ratio of the density of TF mRNA (determined by scanning of autoradiograms) divided by that of GAPDH mRNA after subtraction of background (pBluescript).

$m R N A$ stability analysis. Analysis of TF mRNA stability was performed as previously described (19). Human SMC were stimulated with $10 \%$ FCS for $2 \mathrm{~h}$, washed twice with PBS (0.01 M phosphate, $0.14 \mathrm{M}$ sodium chloride, $\mathrm{pH}$ 7.5) and then treated with actinomycin D $(10 \mu \mathrm{M})$ in the presence of PDGF BB, serum, or defined medium. RNA was collected hourly beginning one $\mathrm{h}$ after treatment, and was analyzed for TF and fibronectin mRNA by blot hybridization as described above. Autoradiograms were scanned using 256 gray levels, and density was analyzed using National Institutes of Health Image 1.57 software. The density of TF bands was normalized to that of fibronectin. Because PDGF and FCS induce additional TF mRNA before maximum inhibition of transcription by actinomycin $\mathrm{D}$, whereas defined medium does not, the density of the normalized initial time point $(1 \mathrm{~h})$ was designated as 1.0 for each condition; subsequent levels were expressed as a fraction of the initial time point. Exponential decay curves were generated using Cricket Graph III software (Computer Associates International, Islandia, NY).

Immunohistochemistry. Polyclonal anti-human TF antibody was raised in rabbits to the extracellular domain (residues 1-218) of TF (soluble TF, sTF) expressed in Escherichia coli as previously described $(6,9,10)$. Immunohistochemical staining used $0.5 \mu \mathrm{g} / \mathrm{ml}$ antisTF antibody or $0.1 \mu \mathrm{g} / \mathrm{ml}$ anti-smooth muscle $\alpha$-actin 1A4 (M851; Dako Corp., Carpenteria, CA). SMC $\left(\sim 6 \times 10^{4}\right.$ cells $\left./ \mathrm{ml}\right)$ were incubated in single-well Permanox or glass slides (Nunc, Inc., Naperville, IL). Slides were fixed in $4 \%$ paraformaldehyde/PBS, $\mathrm{pH} 7.4$, at room temperature, and incubated with appropriate primary antibody for $2 \mathrm{~h}$ at $37^{\circ} \mathrm{C}$. Primary antibodies were detected using a biotin-streptavidin amplified detection system (SuperSensitive Kit; BioGenex Labs, San Ramon, CA) and developed with DAB. Slides were counterstained with hematoxylin, coverslipped, and examined. Positive control slides, nonimmune negative controls, and processing controls were performed for each antigen stain.

In situ DigVIIa binding. DigVIIa was synthesized as previously described (6). As previously noted, the activity of DigVIIa was comparable to that of recombinant FVIIa over a range of concentrations between 0.02 and $640 \mathrm{pM}$ (6). Cells were grown on slides and treated as described above. For most experiments, cells were fixed in $4 \%$ paraformaldehyde/PBS at room temperature for $30 \mathrm{~min}$, and then incubated with $50 \mathrm{nM}$ DigVIIa in Tris buffered saline (TBS) $(0.05 \mathrm{M}$ Tris, $0.1 \mathrm{M}$ sodium chloride, $\mathrm{pH} 7.5)$, containing $5 \mathrm{mM} \mathrm{CaCl}_{2}$ at $37^{\circ} \mathrm{C}$ for $2 \mathrm{~h}$. In some experiments, additional incubation conditions were used, and are described in Results. Cells were washed with TBS + $\mathrm{CaCl}_{2}$ and treated with $4 \%$ paraformaldehyde at room temperature for $10 \mathrm{~min}$. Cells were rinsed in PBS and then incubated with a 1:400 dilution of alkaline phosphatase $(200 \mu \mathrm{g} / \mathrm{ml})$ or peroxidase $(400 \mathrm{mU} /$ $\mathrm{ml}$ ) conjugated antidigoxigenin antibody at $37^{\circ} \mathrm{C}$ for $2 \mathrm{~h}$. Slides were washed with PBS, reacted with the appropriate substrate for $10 \mathrm{~min}$ at room temperature, washed in distilled water, and counterstained with hematoxylin. Controls consisted of substitution of unlabeled FVIIa for DigVIIa, and preincubation of slides with a 10 -fold greater concentration of FVIIa for $1 \mathrm{~h}$ before incubation. Dig VIIa staining was also blocked by preincubation with sTF antibody (6).

In situ DigX binding (6). Slides were incubated with a mixture of $10 \mathrm{nM}$ FVIIa and $25 \mathrm{nM}$ DigX in TBS $+5 \mathrm{mM} \mathrm{CaCl}_{2}$ for $2 \mathrm{~h}$. Cells were fixed in $4 \%$ paraformaldehyde and stained with antidigoxigenin as described for DigVIIa. DigX staining was repeated in the absence of added FVIIa.

Confocal microscopy. Human SMC were seeded on Type I collagen-coated coverslips (Collaborative Biomedical Products, Bedford, MA) or glass slides (Nunc Inc., Naperville, IL). Upon reaching 
confluence, cells were placed in defined medium for $96 \mathrm{~h}$ and then treated for various lengths of time with growth agonists. Coverslips were then fixed and stained with STF antibody as described in immunohistochemistry methods. Primary antibody to sTF was detected with fluoresceinated anti-rabbit IgG antibody (Sigma Chemical Co.). Slides or coverslips were examined using a Leica (Heidelberg, Germany) confocal laser scanning microscope. Intensity profiles (see Fig. 7 insets) were generated along a line traversing the nuclei of the cells, and were based on 8-byte detection (256 gray levels) using Scanware software (Leica Corp.).

Determination of TF activity by factor Xa generation. To measure factor Xa generation on the cell surface, human SMC (passages 5-10) were seeded on gelatin-coated $9.4-\mathrm{cm}^{2}$ plastic chamber slides (Nunc). Upon reaching confluence, cells were placed in defined medium for $96 \mathrm{~h}$ and then treated for various lengths of time with growth agonists. Slides were mounted in a closed-circuit parallel-plate flow chamber with a total volume of $4.0 \mathrm{ml}$, and were perfused continuously using a peristaltic pump in $10 \mathrm{mM}$ Hepes, pH 7.5, $140 \mathrm{mM} \mathrm{NaCl}, 1 \mathrm{~g} /$ liter BSA, and $5 \mathrm{mM} \mathrm{CaCl}$ containing FX $(150 \mathrm{nM})$ and FVIIa $(1.0 \mathrm{nM})$ at a $1.0 \mathrm{ml} / \mathrm{min}$ volumetric flow rate (corresponding to a wall shear rate of $\left.97 \mathrm{sec}^{-1}\right)$. Samples $(40 \mu \mathrm{l})$ were taken from an in-circuit $1.5-\mathrm{ml}$ Eppendorff reservoir every $3 \mathrm{~min}$ for $15 \mathrm{~min}$, and placed sequentially in a 96-well plate with each well containing $100 \mu \mathrm{l}$ of Bicine buffer, $\mathrm{pH}$ 8.5, $1 \mathrm{~g}$ /liter BSA, and $25 \mathrm{mM}$ EDTA to stop the reaction. FXa was assayed by adding $25 \mu \mathrm{l}$ of IPR-pNA $(15 \mathrm{mM})$ to each well and measuring changes in absorption at $405 \mathrm{~nm}$ at $35^{\circ} \mathrm{C}$ in a thermostated ELISA plate reader (Tmax; Molecular Devices, Menlo Park, CA). The concentration of FXa was calculated from the slope of the absorption over time. Fmoles of $\mathrm{TF} / \mathrm{cm}^{2}$ were obtained assuming a $\mathrm{k}_{\mathrm{cat}}$ of the TF-VIIa complex of $300 \mathrm{~min}^{-1}$ at $20^{\circ} \mathrm{C}$. This $\mathrm{k}_{\text {cat }}$ was determined using TF in vesicles containing $20 \%$ phosphatidylserine (PS) and $80 \%$ phosphatidylcholine $(\mathrm{PC})$ at $20^{\circ} \mathrm{C}$. As far as we are aware, $\mathrm{k}_{\text {cat }}$ is not sensitive to the lipid composition. The reaction velocity does depend on the $\mathrm{K}_{\mathrm{m}}$, which varies with lipid composition. Therefore, the TF concentration in cells is an approximation. Relipidation of cell lysates with $35 \mu \mathrm{M}$ (final concentration) $20 \% \mathrm{PS} / 80 \% \mathrm{PC} \mathrm{(20),}$ however, did not significantly change the TF activity (relipidated lysates had $94 \pm 3 \%$ of the activity measured before relipidation, $n=4$ plates).

To compare TF associated with the cell surface versus total cellular TF, confluent plates of quiescent SMC were treated with growth agonists for $4 \mathrm{~h}$, washed $2 \times$ with HBS (10 mM Hepes, pH 7.5, $140 \mathrm{mM}$ $\mathrm{NaCl}$ ), and incubated with $\mathrm{HBS}+4 \mathrm{mM}$ EDTA at $37^{\circ} \mathrm{C}$ for $15 \mathrm{~min}$ to lift cells. Cells were washed twice with $\mathrm{HBS}+5 \mathrm{mM} \mathrm{CaCl}_{2}$ and resuspended in $1 \mathrm{ml} \mathrm{HBS}+5 \mathrm{mM} \mathrm{CaCl}_{2}+1 \mathrm{~g} /$ liter BSA. Cell number was verified by hemocytometer and viability $(98 \pm 2 \%)$ was shown by trypan blue exclusion. Duplicate $160-\mu l$ aliquots were either untreated or lysed by incubation with $15 \mathrm{mM}$ (final concentration) octyl- $\beta-D-g l y-$ copyranoside. FVIIa and FX were then added sequentially to a final volume of $320 \mu \mathrm{l}$, resulting in a final concentration of $7.5 \mathrm{mM}$ octyl$\beta$-D-glycopyranoside, well below its critical micellar concentration of $23 \mathrm{mM}$ (21). A 40- $\mu$ l aliquot was measured every min for $6 \mathrm{~min}$ as described above. All experiments were performed in triplicate at room temperature.

For blocking experiments with S-NHS-A, cells were lifted as described above, washed $2 \times$ with HBS, and resuspended in HBS. $100 \mu \mathrm{l}$ of S-NHS-A (40 mM) in HBS was added to an equal volume of cell suspension and incubated for $1 \mathrm{~h}$ at room temperature. Control tubes contained HBS alone. A 200- $\mu$ l solution containing $100 \mathrm{mM}$ hydroxylamine, $50 \mathrm{mM}$ Tris, $\mathrm{pH} 7.5,5 \mathrm{mM} \mathrm{CaCl}_{2}$, and $1 \mathrm{~g}$ /liter BSA was then added to quench the reaction. Duplicate aliquots were then assayed for Xa generation, as described above, directly, or after lysis with octyl- $\beta$-D-glycopyranoside. Blocking experiments with polyclonal antiSTF antibody were performed in a similar manner. After incubation with $20 \mu \mathrm{g} / \mathrm{ml}$ of antibody, cells were washed $4 \times$ in HBS to remove unbound antibody.

Statistics. Experiments were performed at least three times, and values were presented as the mean \pm SEM. Student's $t$ test was used in the analysis of paired and unpaired means. Unless indicated, all values were significant at $P<0.05$. For nuclear runoff experiments, statistical analysis was performed by one-way ANOVA for repeated measures and Tukey's Method.

\section{Results}

Induction of TF $m R N A$ in human SMC. TF mRNA was barely detectable in quiescent aortic SMC (Fig. 1). FCS induced a marked rise in TF mRNA levels, beginning at $\sim 1 \mathrm{~h}$ and persisting for $\sim 8 \mathrm{~h}$. Neither the degree of confluence (50-100\%) nor the passage number (3-10) had a significant effect on the level or time course of TF mRNA induction by serum. Accumulation of TF mRNA in response to PDGF BB and $\alpha$-thrombin was similar to that seen with $10 \%$ FCS (Fig. 1). In contrast to rat aortic SMC, where the response to PDGF AA is minimal (M.B. Taubman, unpublished observations), the response to PDGF AA was of similar intensity to that of PDGF BB. Also unlike rat aortic SMC (13), the response to angiotensin II was minimal.

Induction of TF mRNA by specific agonists reflected their effects on SMC growth (Table I). FCS, PDGF BB and AA had pronounced effects on DNA synthesis $(10.1 \pm 1.6,6.5 \pm 0.6$, and $8.9 \pm 0.6 \times$ control incorporation of $\left[{ }^{3} \mathrm{H}\right]$ thymidine, respectively) and protein synthesis $(3.2 \pm 0.3,2.7 \pm 0.1$, and $2.6 \pm 0.2 \times$ control incorporation of $\left[{ }^{3} \mathrm{H}\right]$ leucine, respectively). Similar to the effect of $\alpha$-thrombin on rat aortic SMC (16), the thrombin receptor peptide had a hypertrophic effect, markedly increasing protein synthesis $(2.1 \pm 0.2 \times$ control $)$ while having minimal effect on DNA synthesis $(1.3 \pm 0.1 \times$ control $)$. In contrast, angiotensin II had no effect on DNA synthesis $(1.0 \pm 0.1 \times$ control), and had only a small effect on protein synthesis $(1.3 \pm 0.1 \times$ control $)$, suggesting that cultured human arterial SMC possess few angiotensin II receptors.

Because of intrinsic differences in the cellular makeup and responses of arteries from different vascular beds, expression of TF mRNA was also examined in primary cultures of SMC obtained from human coronary arteries. Treatment with $10 \%$ FCS, PDGF AA, PDGF BB, and thrombin receptor peptide induced rapid accumulation of TF mRNA, whereas angiotensin II had a negligible effect (Fig. $1 B$ ). While the predominant TF mRNA was $\sim 2 \mathrm{kB}$, corresponding to mature $\mathrm{TF}$ mRNA, small amounts of a $\sim 3 \mathrm{kB}$ mRNA were also noted. This effect has been shown to be due to inappropriate splicing of TF mRNA, resulting in retention of the first intron (2).

Table I. Growth Agonist Effects on 24-h $\left[{ }^{3} H\right]$ Leucine and Thymidine Incorporation in Human Aortic SMC

\begin{tabular}{lrr}
\hline \multicolumn{1}{c}{ Agonist } & $\begin{array}{c}{\left[{ }^{3} \mathrm{H}\right] \text { Thymidine }} \\
\text { incorporation* }\end{array}$ & $\begin{array}{r}\left.{ }^{3} \mathrm{H}\right] \text { Leucine } \\
\text { incorporation* }\end{array}$ \\
\hline $10 \%$ FCS & $10.06 \pm 1.59$ & $3.17 \pm 0.30$ \\
PDGF BB $(10 \mathrm{ng} / \mathrm{ml})$ & $6.52 \pm 0.56$ & $2.70 \pm 0.06$ \\
PDGF AA $(10 \mathrm{ng} / \mathrm{ml})$ & $8.91 \pm 0.64$ & $2.60 \pm 0.18$ \\
Thrombin receptor peptide $(0.1 \mu \mathrm{M})$ & $1.33 \pm 0.13$ & $2.12 \pm 0.15$ \\
Angiotensin II $(1 \mu \mathrm{M})$ & $0.96 \pm 0.14$ & $1.28 \pm 0.08$ \\
& &
\end{tabular}

* Cells were made quiescent by incubation in defined medium for $48 \mathrm{~h}$ before addition of growth agonists. Values \pm SEM are expressed as the ratio of thymidine or leucine incorporation measured in treated over quiescent cells incubated in fresh defined medium during the 24-h labeling period. Values were significant at $P<0.05$. 


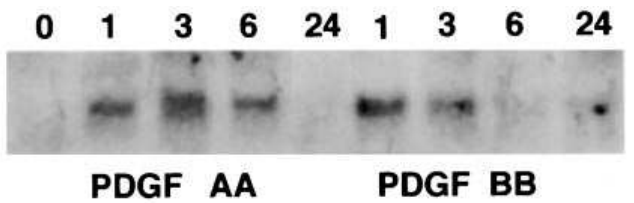

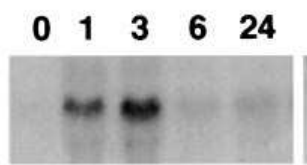

FCS

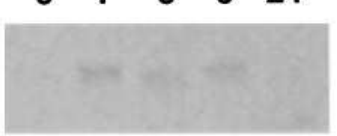

Ang
B

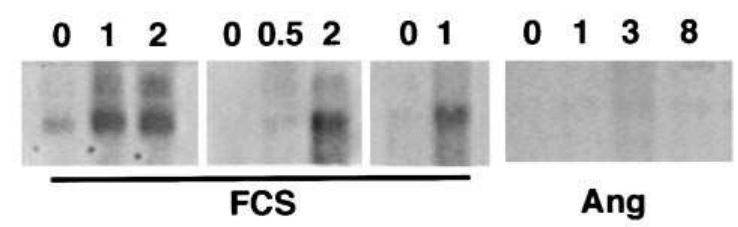

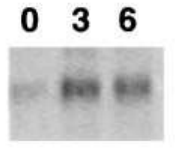

PDGF AA

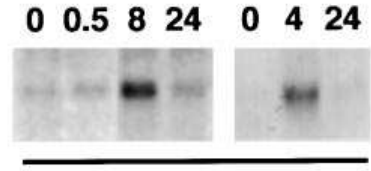

PDGF BB

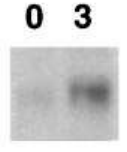

Thr
Figure 1. RNA blot analysis of TF mRNA in human SMC. (A) Aortic SMC Quiescent SMC (incubated in defined media for $48 \mathrm{~h}$; 0 ) were treated for the times indicated (h) with $10 \mathrm{ng} / \mathrm{ml}$ PDGF AA, 10 $\mathrm{ng} / \mathrm{ml}$ PDGF BB, $10 \%$ FCS, $25 \mathrm{nM} \alpha$-thrombin (Thr), or $10^{-6} \mathrm{M}$ angiotensin II (Ang). Blots are representative of triplicate experiments. (B) Coronary artery SMC. Quiescent SMC (0) were treated for the times indicated (h) with $10 \% \mathrm{FCS}, 10 \mathrm{ng} / \mathrm{ml}$ PDGF AA, $10 \mathrm{ng} / \mathrm{ml}$ PDGF BB, $0.1 \mu \mathrm{M}$ of thrombin receptor peptide (Thr), or $10^{-6} \mathrm{M}$ angiotensin II (Ang). Each panel represents primary (i.e., unpassaged) SMC derived from a different coronary artery. Blots, containing $10 \mu \mathrm{g}$ of total RNA/lane, were hybridized to the human TF cDNA and washed at $0.1 \times \mathrm{SSC}, 65^{\circ} \mathrm{C}$. The major hybridizing band corresponds to the $2-\mathrm{kb}$ TF species. A second band of $\sim 3.2 \mathrm{~kb}$, corresponding to a retained intron, is seen in some lanes in response to FCS. It should be noted that the apparent discrepancy in size of the TF mRNA shown for thrombin (Thr) treatment in $A$ is an artifact of gel polymerization, and that all lanes represent the 2-kb mRNA. Equal loading of lanes was verified by hybridization with fibronectin cDNA (not shown).

Role of transcription and $m R N A$ stability in the regulation of TF in $S M C$. As shown in nuclear runoff experiments, PDGF $\mathrm{BB}$ caused a marked rise in TF transcription (Fig. 2) at $30 \mathrm{~min}$ $(5.8 \pm 1.3 \times$ control; $P<0.01)$. By $2 \mathrm{~h}$, TF transcription returned to near baseline $(1.5 \pm 0.4 \times$ control; NS). To evaluate the contribution of mRNA stability to TF accumulation, levels were measured in the presence of the transcription inhibitor

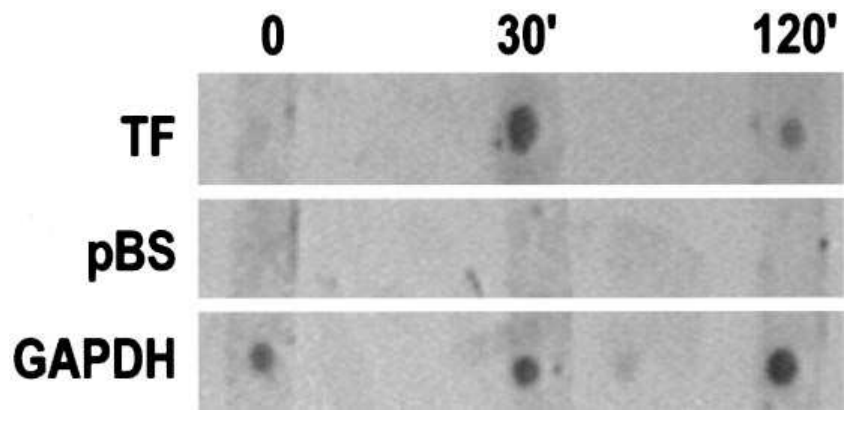

Figure 2. Nuclear runoff transcription analysis of TF mRNA. Nuclei were isolated from untreated quiescent aortic SMC (0) and from those treated for $30 \mathrm{~min}$ or $2 \mathrm{~h}$ with $10 \mathrm{ng} / \mathrm{ml}$ PDGF BB. Radiolabeled nuclei were then hybridized to slot blots containing $5 \mu \mathrm{g}$ of human TF cDNA (TF), bacterial plasmid pBluescript (pBS) DNA, and GAPDH cDNA (GAPDH). Autoradiogram is representative of triplicate experiments.

actinomycin D. As shown in Fig. 3, there was no significant difference in the rate of TF mRNA decay in the presence or absence of growth agonists. The half-life of TF mRNA in human aortic SMC was $\sim 2 \mathrm{~h}$.

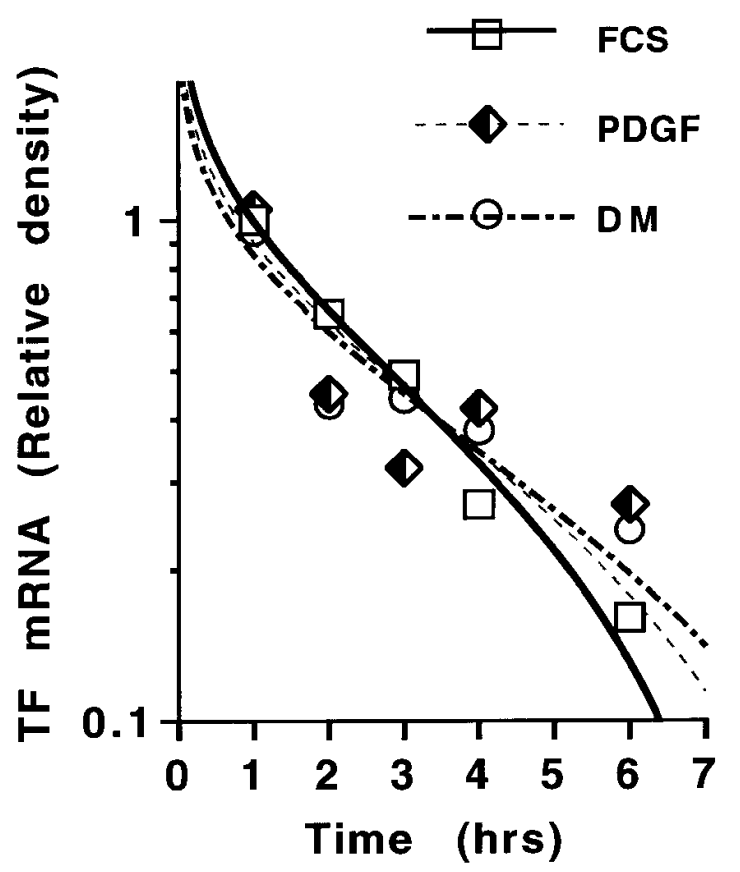

Figure 3. Decay of TF mRNA. Human aortic SMC were treated with $10 \%$ for $2 \mathrm{~h}$ to induce TF mRNA. Plates were washed twice with $\mathrm{PBS}$, and the medium was replaced with either serum-free medium $(D M), 10 \%$ FCS, or $10 \mathrm{ng} / \mathrm{ml}$ PDGF BB (PDGF) in the presence of actinomycin D. At times indicated, cells were harvested and total RNA was collected. $10-\mu \mathrm{g}$ aliquots were subjected to RNA blot analysis for TF and GAPDH. Autoradiograms were scanned using 256 gray scales, and density was analyzed using National Institutes of Health Image 1.43 software. The density of TF bands was normalized to that of GAPDH. Decay curves were generated with the initial time point at $1 \mathrm{~h}$, arbitrarily designated as 1 for each condition. The mRNA half-life was $\sim 2 \mathrm{~h}$, and there was no significant differences between the conditions. Curves were fit using Cricket Graph software. Curves represent the average of three experiments. 


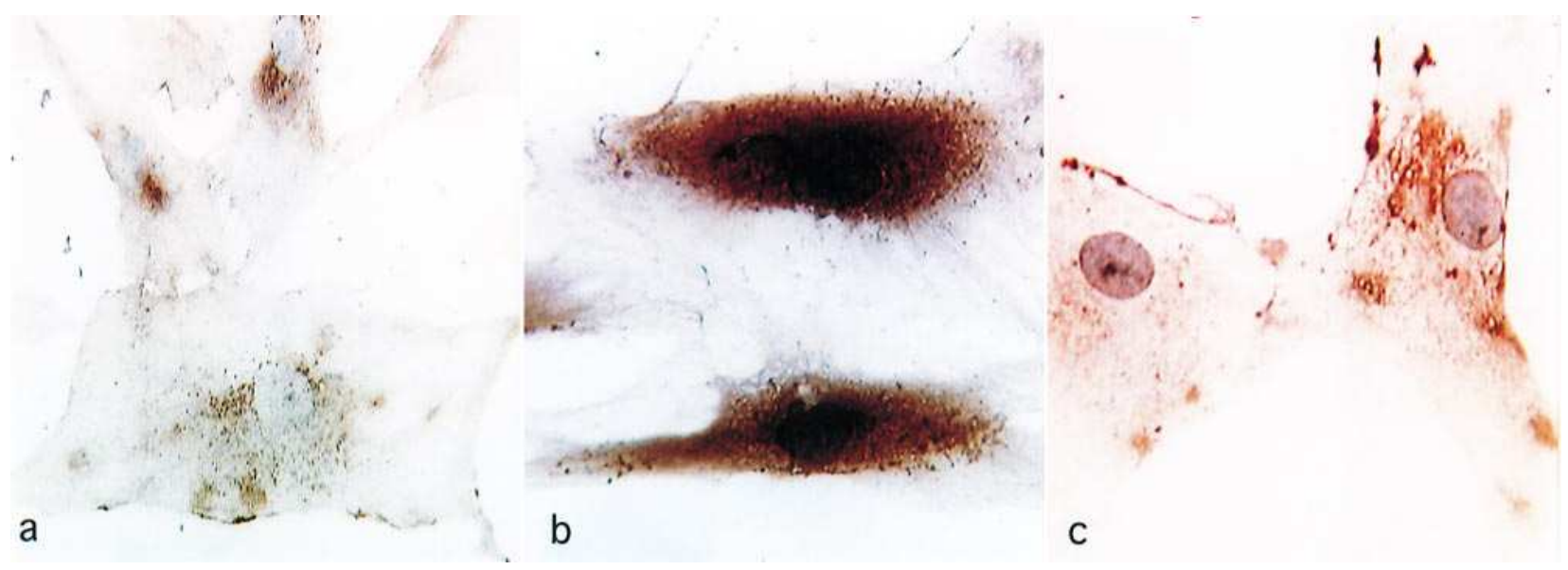

Figure 4. Morphologic analysis of human aortic SMC. (a) Quiescent SMC, stained with rabbit polyclonal anti-human sTF antibody, demonstrating granular perinuclear and edge staining (peroxidase; $400 \times$ original). (b) SMC $4 \mathrm{~h}$ after treatment with PDGF AA (10 ng/ml), stained as in $(a)$, demonstrating marked perinuclear staining $(500 \times$ original). (c) Aortic SMC $16 \mathrm{~h}$ after stimulation with PDGF AA, stained as in $(a)$, demonstrating a patchy membrane distribution $(400 \times$ original $)$.

Accumulation of TF antigen in human SMC. To establish that the rise in TF mRNA in human arterial SMC was accompanied by the synthesis of TF protein, quiescent SMC were examined by immunostaining every hour for $4 \mathrm{~h}$, then every $2 \mathrm{~h}$ for $20 \mathrm{~h}$ after exposure to growth agonists. Minimal TF antigen was detected in quiescent SMC (Fig. $4 a$ ). In contrast, pronounced perinuclear staining of $\mathrm{TF}$ antigen (Fig. $4 \mathrm{~b}$ ) was noted in nearly $100 \%$ of SMC exposed to $10 \%$ FCS, PDGF $\mathrm{AA}$, or $\mathrm{BB}$, or thrombin receptor peptide, beginning at $\sim 2 \mathrm{~h}$ and peaking at 4-6 h. In the case of both PDGF isoforms, as little as $0.1 \mathrm{ng} / \mathrm{ml}$ produced perinuclear staining. Perinuclear staining persisted for $\sim 8-10 \mathrm{~h}$ after agonist stimulation, and then gradually dissipated. 16-24 h after agonist stimulation, TF staining was diminished and localized in patches (Fig. $4 c$ ). By confocal microscopy, TF was visualized predominantly in the perinuclear area $4 \mathrm{~h}$ after PDGF stimulation (Fig. $5 a$ ). TF antigen was also detected diffusely on the ruffled edges of the plasma membrane. Graphic analysis (Fig. $5 a$, inset) of the intensity of immunofluorescent staining along the length of the cell (blue line) through the nucleus showed a bimodal pattern
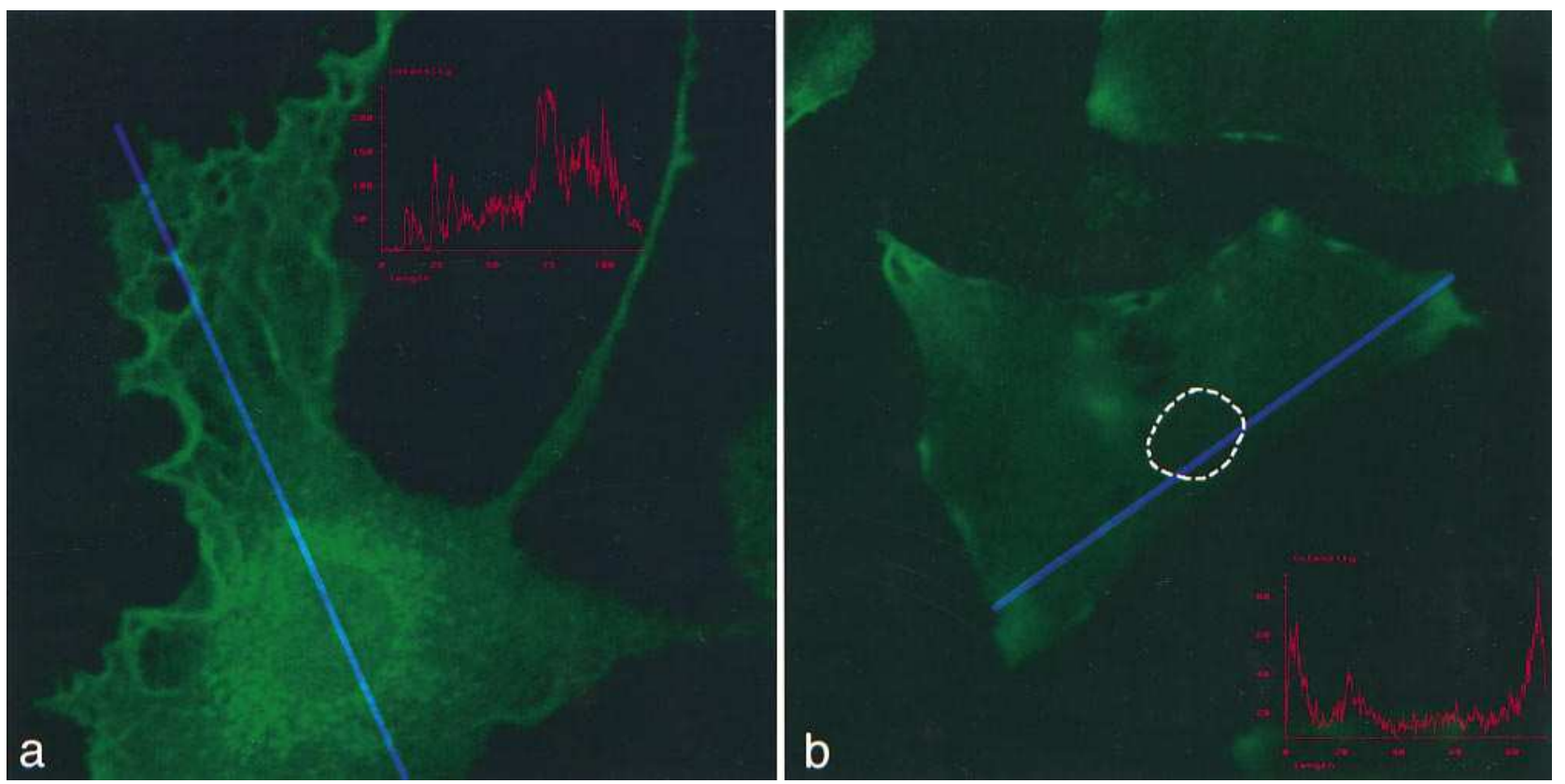

Figure 5. Confocal micrograph of quiescent SMC grown on type 1 collagen coverslip $4 \mathrm{~h}$ after stimulation $(a)$ with PDGF AB (10 ng/ml), stained with immunofluorescent anti-human sTF antibody (fluorescein; $1000 \times$ original) showing perinuclear accumulation of antigen staining with diffuse membrane staining. ( $a$, inset) Graphic analysis of intensity of staining as a function of the cell length along line traversing the nucleus. $(b)$ Confocal micrograph of quiescent human aortic SMC grown on a glass slide, $16 \mathrm{~h}$ after stimulation with PDGF AA (10 ng/ml), stained as in $(a)$ demonstrating surface patches. ( $b$, inset) Graphic analysis of intensity of staining as a function of the cell length along the line traversing the nucleus (nucleus outlined by white dotted line $).(1000 \times$ original). 
with peaks around the nucleus and along the membrane. At $16 \mathrm{~h}$ (Fig. $5 \mathrm{~b}$ ), there was a patchy distribution of antigen staining near or on the membrane, with diminished perinuclear staining. Lines representing intensity measurement traverse the nuclei of the cells longitudinally at both time points, although the nucleus is less well visualized (nucleus outlined) at $16 \mathrm{~h}$ due to paucity of cytoplasmic staining. Similar patterns were observed on glass, Permanox, and collagen- or gelatincoated slides. Likewise, similar patterns were observed when cells were fixed overnight in $4 \%$ paraformaldehyde or for 30 min at $4^{\circ} \mathrm{C}$. Finally, a 30 -min exposure of living SMC monolayers to anti-sTF antibody before fixation and treatment with the secondary antibody did not enhance surface staining. A similar approach showed extensive surface staining in human umbilical vein endothelial cells (data not shown).

Assessment of TF protein by in situ DigVIIa and DigX binding. To characterize the nature of the TF antigen detected above, SMC cultures were examined using an in situ binding assay using DigVIIa or DigX (6). The patterns of DigVIIa (Fig. 6, $a-c$ ) and Dig X (Fig. $6 d$ ) binding were identical to that seen with the antibody: perinuclear localization $2-10 \mathrm{~h}$ after stimulation with growth agonists, and patchy staining near the plasma membrane beginning at $12-16 \mathrm{~h}$. As noted previously (6), staining with DigX was seen only in the presence of added FVIIa. In addition, DigVIIa staining were markedly diminished when 10-fold excesses of recombinant FVIIa and FX were added, respectively. These data suggest that the perinuclear pool of TF can bind its physiologic ligands. To verify that the perinuclear accumulation of $\mathrm{TF}$ antigen was due to de novo transcription of TF, SMC were treated with $10 \mu \mathrm{M}$ actinomycin D before growth factor stimulation. This treatment abolished the perinuclear accumulation of $\mathrm{TF}$ as determined by sTF antibody (not shown) or DigVIIa binding (Fig. 6e). In contrast, treatment with actinomycin $\mathrm{D} 1 \mathrm{~h}$ after agonist induction had no effect on the accumulation of $\mathrm{TF}$ antigen around the nucleus or the subsequent appearance of patches. In additional studies, quiescent SMC were treated with PDGF BB or PDGF AA for $15,30,60,120$, or $180 \mathrm{~min}$. The medium was removed and the cells were washed twice with PBS, and were then incubated in fresh DME + BSA. The cells were examined 4 and $16 \mathrm{~h}$ after the onset of growth factor stimulation. Only $15 \mathrm{~min}$ of exposure to PDGF AA and $30 \mathrm{~min}$ to PDGF $\mathrm{BB}$ were necessary for perinuclear accumulation of TF antigen. Induction of surface TF activity in SMC. To examine the

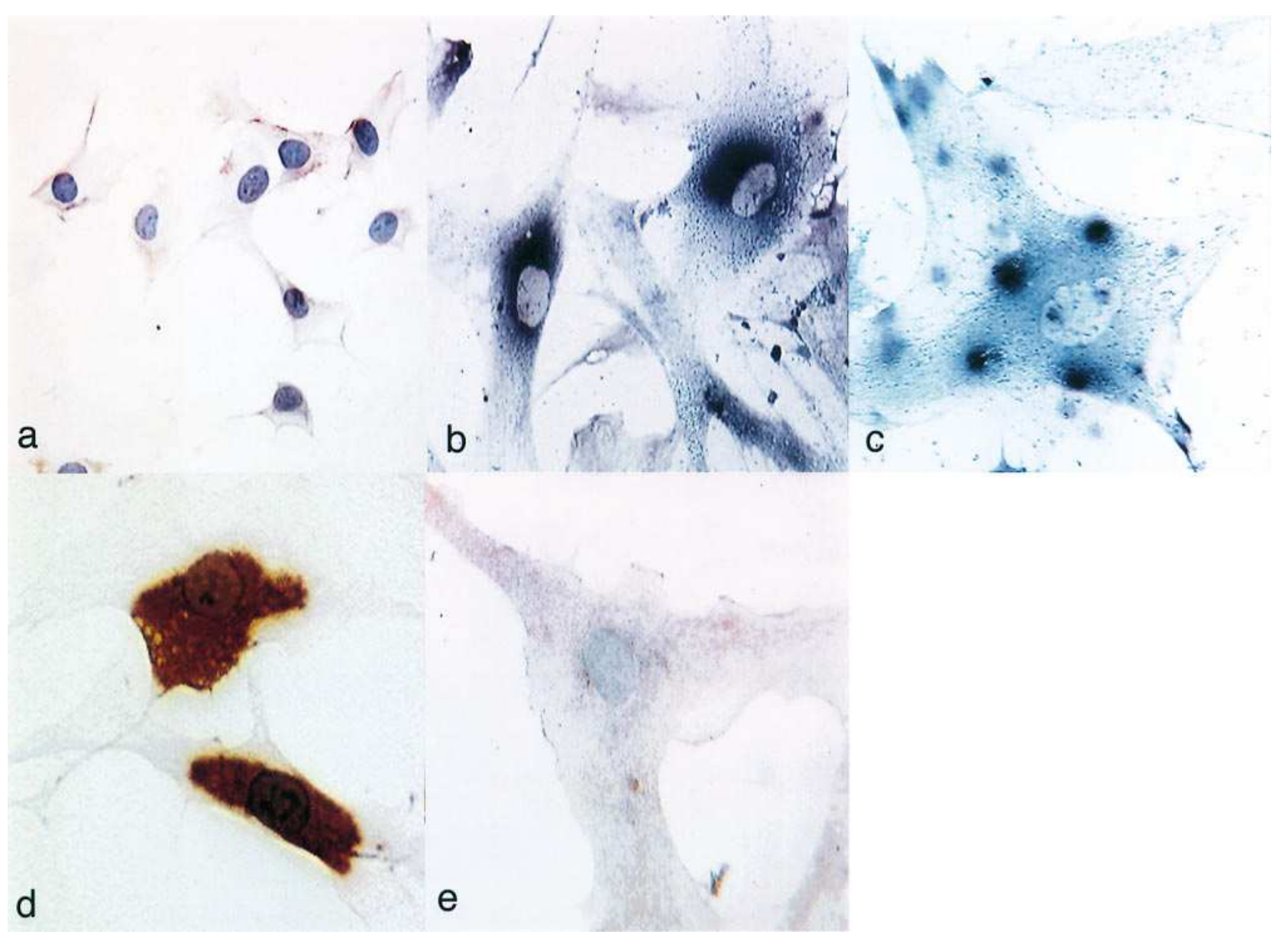

Figure 6. (a) Quiescent SMC stained with DigVIIa (peroxidase; $200 \times$ original). (b) SMC $4 \mathrm{~h}$ after stimulation with PDGF AA, stained with DigVIIa (alkaline phosphatase; $500 \times$ original). (c) SMC $48 \mathrm{~h}$ after treatment with PDGF AA, stained as in $a(400 \times$ original). (d) Quiescent SMC $4 \mathrm{~h}$ after stimulation with PDGF AA, stained with DigX, showing marked perinuclear localization (peroxidase; $500 \times$ original). $(e)$ Quiescent SMC stained as in $a$, pretreated with actinomycin D for $30 \mathrm{~min}$ and then treated $4 \mathrm{~h}$ with PDGF AA, demonstrating minimal staining (400 $\times$ original). 


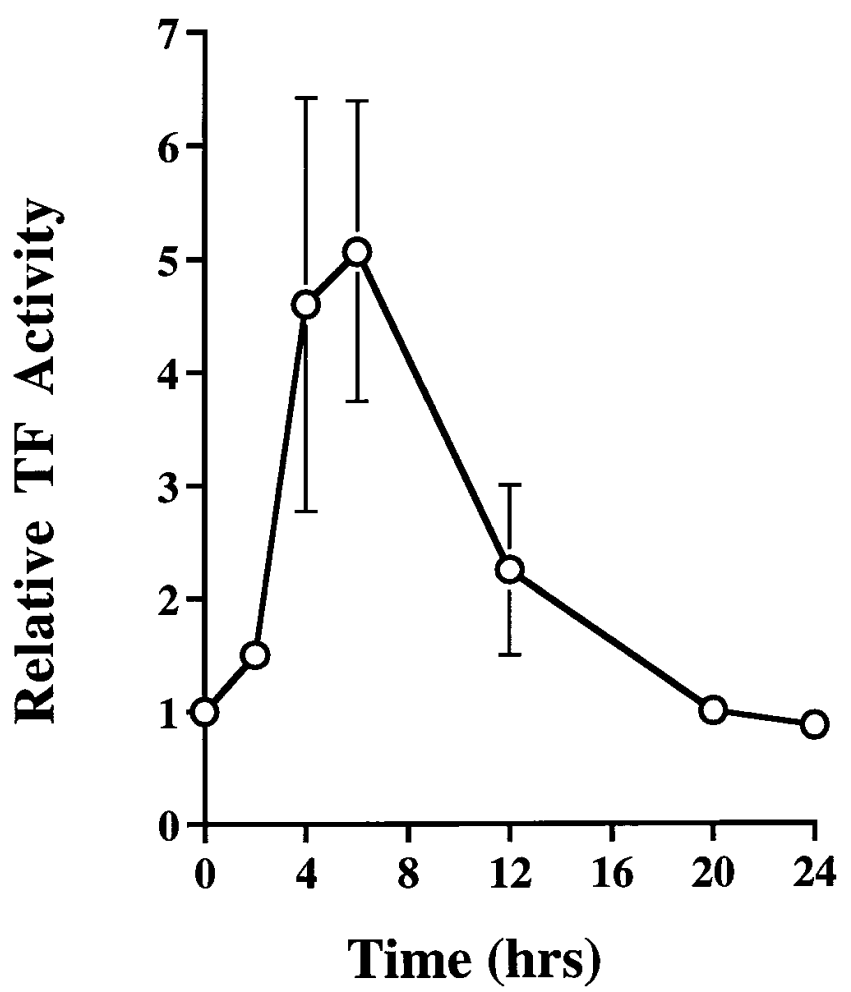

Figure 7. Tissue factor activity on the surface of human aortic SMC. Confluent human aortic SMC (passages 5-9) were plated on gelatincoated single-well slides and placed in serum-free medium for $96 \mathrm{~h}$ before treatment with PDGF. Cells were then perfused in a parallel plate flow chamber with purified clotting factors at low shear for the times given (hrs). Ordinate (relative TF activity) represents the ratio of TF activity (Xa generation in pmoles $/ \mathrm{cm}^{2}$ ) in PDGF-stimulated SMC to activity in perfused untreated replicate slides. Abscissa represents time (hrs). Mean and SEM of triplicate determinations are shown.

temporal expression of TF surface activity in SMC under flow conditions in response to PDGF, SMC monolayers grown on slides were perfused with purified clotting factors in a parallel plate chamber. Xa generation was measured from untreated cells and cells treated with PDGF. PDGF induced an approximately fivefold increase in surface TF activity (Fig. 7) 4-6 h after treatment, with a return to baseline by $20 \mathrm{~h}$. While Fig. 5 represents results pooled from experiments using PDGF AB, $\mathrm{BB}$, and $\mathrm{AA}$ isoforms, all three isoforms induced similar levels of surface TF activity. As calculated from Xa generation, peak surface TF after PDGF stimulation varied between 0.02 and $0.09 \mathrm{fmoles} / \mathrm{cm}^{2}$ of a confluent SMC monolayer, corresponding to $\sim(1-4.5) \times 10^{3} \mathrm{TF}$ molecules/cell. In all experiments, the amount of surface activity $/ \mathrm{cm}^{2}$ at $4 \mathrm{~h}$ was $<10 \%$ of the TF measured in cell lysates from plates grown under identical conditions.

To determine further the relative amounts of surface and total cellular TF activity, cells were treated with PDGF for $4 \mathrm{~h}$ and TF activity was then measured simultaneously from aliquots of intact SMC and SMC lysed with octyl- $\beta$-D-glycopyranoside. The activity of intact SMC was $22 \pm 2 \%(n=6)$ of that measured from lysed cells. A similar partitioning was found when cells were lysed by freeze-thawing $(18 \pm 4 \%, n=4)$.

Identification of TF in latent and intracellular pools. Recent studies have suggested that for some cell types, much of the TF activity exists in a latent form on or near the cell surface (2229). To evaluate better the partitioning of TF in human SMC, PDGF-treated cells were incubated with anti-sTF antibody to bind and inhibit surface TF. After extensive washing, TF activity was measured in intact cells (surface activity) and in cells lysed with octyl- $\beta$-D-glycopyranoside (total activity). Results were compared to duplicate cultures not treated with antibody. Similar to previous experiments, $\sim 15 \%$ of total TF activity was measurable on the surface of intact cells (Table II). The antibody blocked $>95 \%$ of this surface activity. $37 \%$ of total TF activity measured in detergent-treated cells remained after treatment with antibody. This activity was presumably not accessible on the surface, and therefore was considered intracellular. The remaining $48 \%$ of $\mathrm{TF}$ activity was blocked by antibody treatment and therefore was considered as latent surface TF. Because binding of antibody to TF is reversible, a second blocking approach was used to verify the results obtained with anti-sTF. S-NHS-A does not enter cells, and irreversibly binds and inactivates TF. Pretreatment with S-NHS-A blocked $>97 \%$ of the surface TF activity, and produced results similar to that obtained with antibody: $\sim 24 \%$ of total TF active on the surface, $\sim 50 \%$ latent surface TF, and $\sim 26 \%$ intracellular TF.

\section{Discussion}

This report is the first of which we are aware that examines induction of TF by growth agonists in human arterial (aortic and coronary) SMC. Most significantly, we report the presence of three distinct cellular pools of potentially active TF after growth factor stimulation. A parallel plate chamber was used to examine the expression of active TF on the surface of human SMC under flow conditions. The results of these studies suggest that induction of surface TF activity in unperturbed monolayers is transient and represents only a small percentage of the total cellular TF. The remainder of the TF is present in an intracel-

Table II. Partitioning of TF Activity in Human Aortic SMC

\begin{tabular}{lcc}
\hline & \multicolumn{2}{c}{ Percent activity } \\
\cline { 2 - 3 } \multicolumn{1}{c}{ Blocking agent } & Anti-sTF antibody & S-NHS-A \\
\hline Total TF* & 100 & 100 \\
Surface $\mathrm{TF}^{\ddagger}$ & $14.9 \pm 2.3$ & $24.3 \pm 4.2$ \\
Intracellular TF & $37.1 \pm 1.8$ & $26.2 \pm 7.2$ \\
Latent $\mathrm{TF}^{\|}$ & $48.0 \pm 3.4$ & $49.5 \pm 3.2$
\end{tabular}

SMC monolayers, incubated in defined medium for $48 \mathrm{~h}$, were treated for $4 \mathrm{~h}$ with $10 \mathrm{ng} / \mathrm{ml}$ PDGF AB, lifted with EDTA, washed, and suspended in $1 \mathrm{ml}$ buffer. ${ }^{*}$ Total activity (Xa generation) was measured from aliquots lysed with detergent ( $15 \mathrm{mM}$ octyl- $\beta$-D-glycopyranoside) and is designated as $100 \%$. ${ }^{*}$ Surface activity was measured from identical aliquots not lysed with detergent, and is expressed as a percentage of total activity $( \pm \mathrm{SEM}) .{ }^{\S}$ To assay for intracellular TF, aliquots were incubated in suspension for $1 \mathrm{~h}$ at $37^{\circ} \mathrm{C}$ with blocking agents (anti-sTF antibody or S-NHS-A). After vigorous washing, total and surface activity were measured from lysed and unlysed aliquots. Both blocking procedures inhibited $>95 \%$ of surface activity. Intracellular activity was considered as the activity measured in cell lysates after blocking, and is expressed as a percentage of total activity measured in unblocked

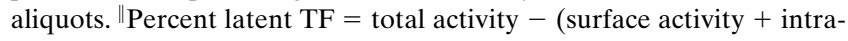
cellular activity). 
lular pool and as latent TF on the cell surface. The limited availability of active TF on the surface of SMC may be an important adaptive mechanism for limiting the procoagulant potential of the vessel wall.

The time course for induction of TF mRNA in aortic SMC by growth agonists was similar to that found in human monocytes (13) and endothelial cells (14), beginning at $\sim 1 \mathrm{~h}$ and remaining elevated for $\sim 8 \mathrm{~h}$, but was different from rat aortic SMC (16), where induction of TF begins at $\sim 15 \mathrm{~min}$, peaks between 75 and $90 \mathrm{~min}$, and returns to baseline within $3 \mathrm{~h}$. This result suggests that the time course of $\mathrm{TF}$ expression is more species- than cell type-specific. SMC in different vascular beds as well as within atherosclerotic lesions exhibit marked differences in morphology and gene expression when compared with normal medial SMC (30). Therefore, it is important to verify that induction of TF by growth agonists in coronary arterial SMC, where thrombosis is particularly critical, is similar to that found in aortic SMC. Only a few plates of primary SMC were available from human coronary arteries since these cells are not readily passaged, resulting in only one or two time points per patient. Thus, while this study does not establish the precise pattern of induction of TF in human coronary artery SMC, it does demonstrate that TF induction in coronary SMC is pronounced and responsive to the same agonists as seen for aortic SMC.

The response of human arterial SMC to PDGF AA homodimer is of particular interest. PDGF, a potent SMC chemoattractant and mitogen, is hypothesized to play an important role in vessel injury (31). PDGF AB is released from platelets and leukocytes recruited to the site of vessel injury. PDGF AA is induced in the cells of the vessel wall in response to acute injury (32). Recent data have suggested that there are important differences in the function and regulation of the PDGF A and B chains. For example, PDGF BB induces chemotaxis of primate (33) and human SMC (34), whereas AA exhibits no chemotactic activity. In most studies, PDGF BB is a potent mitogen for rat aortic SMC, whereas PDGF AA has a minimal effect. This fact is attributable to low levels of PDGF $\alpha$ receptors in rat aortic SMC. In rodent models of balloon arterial injury, PDGF AA, but not $\mathrm{BB}$, is transiently induced in medial and intimal SMC (33). The weak response of cultured rat aortic SMC to PDGF AA has raised questions concerning the importance of the induction of PDGF AA in the vessel wall. In this study, however, cultured human arterial SMC synthesized DNA equally well in response to PDGF BB and AA homodimers. Most importantly, both isoforms were potent inducers of TF mRNA and protein. This study thus supports the concept that PDGF, in addition to its mitogenic and chemoattractive properties, may play an important role in regulating intraarterial thrombosis. In particular, PDGF AA induced within the vessel wall by injury $(31,33)$ may provide an important proliferative and procoagulant stimulus.

A feature of this study is the use of DigVIIa and DigX as an alternative to antibody to localize cellular TF. As previously reported (6), this approach has high specificity for TF in that binding is blocked by anti-sTF antibody and unlabeled FVIIa. In addition, staining requires conditions necessary for normal TF-ligand interactions, e.g., the presence of $\mathrm{Ca}^{2+}$ to bind DigVIIa and the presence of FVIIa to bind DigX (6). In this study, DigVIIa and DigX binding yielded staining patterns similar to that of TF antibody, and in particular recapitulated the prominent perinuclear staining induced by agonists and ac- cumulation of surface patches. This result suggests that the visible TF antigen located in these compartments contains intact binding sites for FVIIa and FX, and thus is a source of potentially active TF. In addition to identifying TF in human cells, human DigVIIa and DigX bind specifically to cells from heterologous species such as pig, rat, rabbit, and mouse (data not shown), and thus provides a powerful tool for examining the expression of TF in cultured cells.

TF antigen accumulated in a distinct perinuclear pattern 2-4 $\mathrm{h}$ after stimulation with growth agonists, and remained predominantly perinuclear for $8-10 \mathrm{~h}$ before decreasing. At subsequent times, TF antigen was most prominent in patches along the plasma membrane. In comparison to the intensity of perinuclear staining, surface staining appeared minimal at all times. The relatively low intensity of surface TF staining contrasts with the finding that antibody blocked $\sim 63 \%$ of total TF activity (Table II). This apparent discrepancy is likely the result of a disperse distribution of TF molecules on the cell surface, as suggested by confocal microscopy. Given the relatively large surface area of the plasma membrane, this would result in a relatively low density of TF molecules on the surface compared with a high density of TF around the nucleus or in surface patches. The intensity of staining is likely to be related to the density of TF molecules, and may even require a threshold before being visible by light microscopy. Therefore, TF may be most apparent by immunohistochemical techniques in the perinuclear area or in dense surface patches, even though the total amount of TF may be greater on the cell surface, as suggested by the activity measurements. Although $\sim 30 \%$ of total TF activity was found to be intracellular, it is also possible that some of the TF antigen identified by immunohistochemistry is not active. For example, electron micrographs have demonstrated the presence of intracellular TF in lysozymes as well as in the perinuclear cytoplasm (27). The lack of prominent surface staining does not appear to be an artifact of fixation in that similar patterns were seen when cells were fixed at $4^{\circ} \mathrm{C}$ and $20^{\circ} \mathrm{C}$. More importantly, exposure of living cells to the antibody before fixation did not alter the intensity of surface staining.

The accumulation of patches of TF on the cell surface is intriguing in that they are most prominent at a time (10-12 $\mathrm{h}$ after agonist stimulation) when surface TF activity is minimal. These patches may represent coalescence of surface TF into structures earmarked for internalization and degradation, as suggested by Mulder et al. (27). These patches may also represent TF multimers, which have been hypothesized to be inactive (23). This study also highlights the importance of measuring TF activity in different cellular compartments. Whereas immunochemical studies were helpful in identifying a previously undescribed intracellular pool, they failed to reflect accurately the partitioning of TF between the surface and the perinuclear cytoplasm.

In this study, TF activity (Xa generation) was measured on the surface of unperturbed SMC monolayers under flow conditions. This approach has been used previously to study surface TF expression in endothelial cells and fibroblasts $(35,36)$. This approach may more accurately reflect active TF accessible on the cell surface under physiologic conditions, because the SMC remain as a monolayer together with the extracellular matrix rather than being subjected to treatments that either dissociate them into single cells, or that chemically alter the monolayer. In addition, the kinetics of TF activation differ 
markedly under conditions of flow vs. static measurements (36). Under flow conditions, PDGF isoforms transiently induced surface TF activity, peaking between 4 and $6 \mathrm{~h}$. Maximum surface TF was $\sim 10 \%$ of the total TF activity from cell lysates. The flow data suggest that the majority of potentially active TF is not accessible on the cell surface under physiologic conditions. Moreover, they demonstrate that induction of surface TF activity by PDGF is transient. Human arterial SMC therefore appear to be particularly effective in limiting the amount of active TF available on their surface.

In EDTA-dissociated cells, surface activity was $\sim 20 \%$ of total. The difference likely reflects the fact that after EDTA dissociation, the entire cell surface is accessible to bind ligand, whereas unperturbed monolayers presumably have only half of their surface accessible. These results differ somewhat from those recently reported by Mulder et al. (27) for human umbilical vein SMC, where the surface activity of dissociated cells was found to be far greater than that measured on intact cell monolayers. This study differs not only in the arterial origin of the cells, but perhaps more importantly, in that Xa generation was measured under continuous flow. Measurement of surface TF activity may also be affected by colocalization with tissue factor pathway inhibitor (TFPI) (29). All of the TF activity measurements in this study were made after cells were treated with EDTA under conditions which dissociate bound TFPI.

Previous studies in a variety of cell types have found that a substantial portion of TF is not active on the surface of unperturbed monolayers, and have suggested that much of the TF is encrypted (22-29) on the cell surface. This encrypted TF can be activated by processes that alter the structure or phospholipid composition of the cell membrane, such as detergent treatment or cell lysis. This study suggests that, after growth factor stimulation, human arterial SMC accumulate TF in a potentially active intracellular pool as well as in a latent form on the cell surface. The intracellular pool contains as much as $37 \%$ of the total TF activity found in detergent-treated cells, and thus represents a significant fraction of total cellular TF. This result contrasts with previous studies. For example, Drake et al. (25) found no intracellular accumulation of TF antigen in human monocytes. Studies in ovarian carcinoma cells (26) and fibroblasts (24) suggested that these cells also lacked significant intracellular TF. Mulder et al. (27), in an elegant study in human SMC of umbilical vein origin, demonstrated that latent TF was present in caveolae. This study focused largely on the cell membrane and did not address intracellular TF activity, although intracellular TF antigen was seen in lysosomal structures around the nucleus.

Partitioning of TF among active, latent, and intracellular pools did not change significantly when cells were lysed by freeze-thawing, rather than by detergent treatment, suggesting that the activation of latent tissue factor was due largely to disruption of the cell membrane and not due to detergent-specific changes in membrane phospholipids $(24,26)$. Furthermore, no additional TF activity was generated by relipidating with PS/PC. This result suggests that there is no significant pool of TF, either on the cell surface or intracellular, that is inactive or has reduced activity by virtue of not being complexed to the appropriate phospholipids. TF in an intracellular pool, as well as TF encrypted on the cell surface, may provide a rich source of procoagulant activity under conditions associated with SMC injury, such as balloon angioplasty and intra-arterial stenting or acute plaque rupture.
The perinuclear accumulation of TF protein requires TF transcription, in that it was completely blocked by pretreatment with actinomycin D. Moreover, it did not require continuous exposure to growth agonists: exposure of SMC to 15 and 30 min of PDGF AA or BB provided the necessary signals for induction of TF mRNA and protein. This time course is consistent with the data obtained from nuclear run-on analyses, which demonstrated that PDGF-induced TF transcription in SMC occurs within $30 \mathrm{~min}$. Treatment with actinomycin D $1 \mathrm{~h}$ after exposure to PDGF had no effect on the perinuclear accumulation of TF or its subsequent appearance as membrane patches, indicating that additional transcription is not required for normal $\mathrm{TF}$ processing. In contrast to the importance of transcription, increases in mRNA stability did not appear to play a role in accumulation of TF mRNA in human aortic SMC. This result differs from human umbilical endothelial cells, where the degree of posttranscriptional stabilization was shown to be agonist-dependent. Crossman et al. (14) found that the accumulation of TF mRNA in endothelial cells in response to LPS was largely a result of increased mRNA stability, whereas induction by phorbol ester was not. In monocytes, induction of TF mRNA by LPS (37) was due to increases in transcription and mRNA stability. It should be noted that previous studies using rat aortic SMC (19) did not examine the role of transcription or mRNA stability in the accumulation of TF mRNA, and that to our knowledge, this is the first such study performed on human SMC.

SMC are the major cellular component of the arterial wall, and are found in abundance in human atherosclerotic plaques. After acute arterial injury, SMC are often exposed to circulating blood. These results suggest that a short exposure to any PDGF isoform may be sufficient to induce a transient procoagulant state on the surface of exposed SMC. In addition, SMC contain pools of intracellular and latent surface TF, which may be exposed in more severe injuries associated with cell damage. This fact may be particularly important in thrombotic events associated with plaque rupture, such as myocardial infarction and unstable angina. The presence of an intracellular pool may be particularly important, because it is likely to be protected from extracellular inhibitors of TF, such as TFPI. In contrast, latent surface TF may still be able to complex with such inhibitors $(26,29)$ in vivo, and therefore may not be able to fully contribute to enhanced thrombogenicity. It remains necessary to establish whether similar pools exist in SMC in vivo. Elucidation of the mechanisms involved in the transcription and cellular partitioning of TF in SMC may provide important insights into regulating arterial thrombosis and coagulation in the atherosclerotic artery.

\section{Acknowledgments}

We gratefully acknowledge the technical contributions of Singanallore V. Thiruvikraman and Veronica Gulle to the work reported in this manuscript. We wish also to thank Dr. Scott Henderson for his expert assistance with the confocal microscopy.

This research was supported in part by National Institutes of Health grants HL54469 and HL29019 (M.B. Taubman, Y. Nemerson) and a grant from Dr. Karl Thomae, GmbH (Biberach, Germany). A.D. Schecter is a recipient of National Institutes of Health National Research Service Award HL09402. 


\section{References}

1. Nemerson, Y. 1988. Tissue factor and hemostasis. Blood. 71:1-8.

2. Edgington, T.S., N. Mackman, K. Brand, and W. Ruf. 1991. The structural biology of expression and function of tissue factor. Thromb. Haemost. 66: $67-79$

3. Rapaport, S.I., and L.V. Rao. 1995. The tissue factor pathway: how it has become a "prima ballerina." Thromb. Haemost. 74:7-17.

4. Marmur, J.D., M. Rossikhina, A. Guha, B. Fyfe, V. Friedrich, M. Mendlowitz, Y. Nemerson, and M.B. Taubman. 1993. Tissue factor is rapidly induced in arterial smooth muscle after balloon injury. J. Clin. Invest. 91:2253-2259.

5. Pawashe, A.B., P. Golino, G. Ambrosio, F. Migliaccio, M. Ragni, I. Pascucci, M. Chiariello, R. Bach, A. Garen, W.K. Konigsberg, et al. 1994. A monoclonal antibody against rabbit tissue factor inhibits thrombus formation in stenotic injured rabbit carotid arteries. Circ. Res. 74:56-63.

6. Thiruvikraman, S.V., A. Guha, J. Roboz, M.B. Taubman, Y. Nemerson, and J.T. Fallon. 1996. In situ localization of tissue factor in human atherosclerotic plaques by binding of digoxigenin-labeled factors VIIa and X. Lab. Invest. 75:451-461.

7. Speidel, C.M., P.R. Eisenberg, W. Ruf, T.S. Edgington, and D.R. Abendschein. 1995. Tissue factor mediates prolonged procoagulant activity on the luminal surface of balloon-injured aortas in rabbits. Circulation. 92:3323-3330.

8. Wilcox, J.N., K.M. Smith, S.M. Schwartz, and D. Gordon. 1989. Localization of tissue factor in the normal vessel wall and in the atherosclerotic plaque. Proc. Natl. Acad. Sci. USA. 86:2839-2843.

9. Marmur, J.D., S.V. Thiruvikraman, B.S. Fyfe, A. Guha, S.K. Sharma, J.A. Ambrose, J.T. Fallon, Y. Nemerson, and M.B. Taubman. 1996. Identification of active tissue factor in human coronary atheroma. Circulation. 94:12261232.

10. Moreno, P.R., V.H. Bernardi, J. Lopez-Cuellar, A.M. Murcia, I.F. Palacios, H.K. Gold, R. Mehran, S.K. Sharma, Y. Nemerson, V. Fuster, and J.T. Fallon. 1996. Macrophages, smooth muscle cells, and tissue factor in unstable angina. Implications for cell-mediated thrombogenicity in acute coronary syndromes. Circulation. 94:3090-3097.

11. Annex, B.H., S.M. Denning, K.M. Channon, M.H. Sketch, Jr., R.S. Stack, J.H. Morrissey, and K.G. Peters. 1995. Differential expression of tissue factor protein in directional atherectomy specimens from patients with stable and unstable coronary syndromes. Circulation. 91:619-622.

12. Fernandez-Ortiz, A., J.J. Badimon, E. Falk, V. Fuster, B. Meyer, A. Mailhac, D. Weng, P.K. Shah, and L. Badimon. 1994. Characterization of the relative thrombogenicity of atherosclerotic plaque components: implications for consequences of plaque rupture. J. Am. Col. Cardiol. 23:1562-1569.

13. Brand, K., B.J. Fowler, T.S. Edgington, and N. Mackman. 1991. Tissue factor mRNA in THP-1 monocytic cells is regulated at both transcriptional and posttranscriptional levels in response to lipopolysaccharide. Mol. Cell. Biol. 11: 4732-4738.

14. Crossman, D.C., D.P. Carr, E.G. Tuddenham, J.D. Pearson, and J.H. McVey. 1990. The regulation of tissue factor mRNA in human endothelial cells in response to endotoxin or phorbol ester. J. Biol. Chem. 265:9782-9787.

15. Miletich, J.P., G.J. Broze, and P.W. Majerus. 1980. The synthesis of sulfated dextran beads for isolation of human plasma coagulation factors II, IX, and X. Anal. Biochem. 105:304-310.

16. Taubman, M.B., J.D. Marmur, C.L. Rosenfield, A. Guha, S. Nichtberger, and Y. Nemerson. 1993. Agonist-mediated tissue factor expression in cultured vascular smooth muscle cells. Role of $\mathrm{Ca} 2+$ mobilization and protein kinase C activation. J. Clin. Invest. 91:547-552.

17. Patton, W.F., H. Erdjument-Bromage, A.R. Marks, P. Tempst, and M.B. Taubman. 1995. Components of the protein synthesis and folding machinery are induced in vascular smooth muscle cells by hypertrophic and hyperplastic agents. Identification by comparative protein phenotyping and microsequencing. J. Biol. Chem. 270:21404-21410.

18. Spicer, E.K., R. Horton, L. Bloem, R. Bach, K.R. Williams, A. Guha, J. Kraus, T.C. Lin, Y. Nemerson, and W.H. Konigsberg. 1987. Isolation of cDNA clones coding for human tissue factor: primary structure of the protein and cDNA. Proc. Natl. Acad. Sci. USA. 84:5148-5152.
19. Taubman, M.B., B.J. Rollins, M. Poon, J. Marmur, R.S. Green, B.C. Berk, and B. Nadal-Ginard. 1992. JE mRNA accumulates rapidly in aortic injury and in platelet-derived growth factor-stimulated vascular smooth muscle cells. Circ. Res. 70:314-325.

20. Bach, R., R. Gentry, and Y. Nemerson. 1986. Factor VII binding to tissue factor in reconstituted phospholipid vesicles: induction of cooperativity by phosphatidylserine. Biochemistry. 25:4007-4020.

21. De Grip, W.J., and P.H.M. Bovee-Guerts. 1979. Synthesis and properties of alkylglucosides with mild detergent action: improved synthesis and purification of $\beta$-1-octyl-, -nonyl-, and -decyl-glucose. Synthesis of $\beta$-1-undecylglucose and $\beta$-1-dodecylmaltose. Chem. Phys. Lipids. 23:321-335.

22. Maynard, J.R., C.A. Heckman, F.A. Pitlick, and Y. Nemerson. 1975. Association of tissue factor activity with the surface of cultured cells. J. Clin. Invest. 55:814-824.

23. Bach, R.R., and C.F. Moldow. 1997. Mechanism of tissue factor activation on HL-60 cells. Blood. 89:3270-3276.

24. Carson, S.D. 1996. Manifestation of cryptic fibroblast tissue factor occurs at detergent concentrations which dissolve the plasma membrane. Blood Coagul. Fibrinolysis. 7:303-313.

25. Drake, T.A., W. Ruf, J.H. Morrissey, and T.S. Edgington. 1989. Functional tissue factor is entirely cell surface expressed on lipopolysaccharide-stimulated human blood monocytes and a constitutively tissue factor-producing neoplastic cell line. J. Cell Biol. 109:389-395.

26. Le, D.T., S.I. Rapaport, and L.V. Rao. 1992. Relations between factor VIIa binding and expression of factor VIIa/tissue factor catalytic activity on cell surfaces. J. Biol. Chem. 267:15447-15454.

27. Mulder, A.B., J.W. Smit, V.J. Bom, N.R. Blom, M.H. Ruiters, M.R. Halie, and J. van der Meer. 1996. Association of smooth muscle cell tissue factor with caveolae. Blood. 88:1306-1313.

28. Greeno, E.W., R.R. Bach, and C.F. Moldow. 1996. Apoptosis is associated with increased cell surface tissue factor procoagulant activity. Lab. Invest. 75:281-289.

29. Sevinsky, R.J., M.V.L. Rao, and W. Ruf. 1996. Ligand-induced protease receptor translocation into caveolae: a mechanism for regulating cell surface proteolysis of the tissue factor-dependent coagulation pathway. J. Cell Biol. 133:293-304.

30. Kocher, O., F. Gabbiani, G. Gabbiani, M.A. Reidy, M.S. Cokay, H. Peters, and I. Huttner. 1991. Phenotypic features of smooth muscle cells during the evolution of experimental carotid artery intimal thickening. Biochemical and morphologic studies. Lab. Invest. 65:459-470.

31. Ferns, G.A., E.W. Raines, K.H. Sprugel, A.S. Motani, M.A. Reidy, and R. Ross. 1991. Inhibition of neointimal smooth muscle accumulation after angioplasty by an antibody to PDGF. Science (Wash. DC). 253:1129-1132.

32. Koyama, N., C.E. Hart, and A.W. Clowes. 1994. Different functions of the platelet-derived growth factor-alpha and -beta receptors for the migration and proliferation of cultured baboon smooth muscle cells. Circ. Res. 75:682691

33. Kraiss, L.W., E.W. Raines, J.N. Wilcox, R.A. Seifert, T.B. Barrett, T.R Kirkman, C.E. Hart, D.F. Bowen-Pope, R. Ross, and A.W. Clowes. 1993. Regional expression of the platelet-derived growth factor and its receptors in a primate graft model of vessel wall assembly. J. Clin. Invest. 92:338-348.

34. Jiang, B., S. Yamamura, P.R. Nelson, L. Mureebe, and K.C. Kent. 1996. Differential effects of platelet-derived growth factor isotypes on human smooth muscle cell proliferation and migration are mediated by distinct signaling pathways. Surgery. 120:427-431.

35. Kirchhofer, D., K.S. Sakariassen, M. Clozel, T.B. Tschopp, P. Hadvary, Y. Nemerson, and H.R. Baumgartner. 1993. Relationship between tissue factor expression and deposition of fibrin, platelets, and leukocytes on cultured en dothelial cells under venous blood flow conditions. Blood. 81:2050-2058.

36. Grabowski, E.F., D.B. Zuckerman, and Y. Nemerson. 1993. The functional expression of tissue factor by fibroblasts and endothelial cells under flow conditions. Blood. 81:3265-3270.

37. Donovan-Peluso, M., L.D. George, and A.C. Hassett. 1994. Lipopolysaccharide induction of tissue factor expression in THP-1 monocytic cells. Protein-DNA interactions with the promoter. J. Biol. Chem. 269:13611369. 